\title{
THE INFLUENCE OF CHANGES IN THE GEOMETRY OF THE TOOTH SURFACE OF THE PINION BEVEL GEAR ON THE KINEMATIC ACCURACY OF PAIR MESH
}

\author{
Mieczysław PŁOCICA*, Jadwiga PISULA* \\ *Department of Mechanical Design, Rzeszow University of Technology, Al. Powstańców Warszawy 12, 35-959 Rzeszów, Poland \\ mplocica@prz.edu.pl, jpisula@prz.edu.pl
}

\begin{abstract}
The paper describes the possibilities of bevel gears kinematics design on the basis of the motion graph and improving modifications to cut the pinion teeth flanks. The result is the ability to increase the accuracy of the kinematic transmission. The issue of changing the geometry of the pinion gear is considered in respect of a gear intended for the use in aviation, which requires the cooperation of high quality meshing. The basic geometric features that have been modified include the profile angle, the angle of tooth line, crowning transverse and longitudinal and lateral surface twist angle of the tooth. The modification of each of the selected geometrical parameters has had a different effect on the chart of transmission. It has been shown that the effect of the intended changes in the geometry of the pinion may reduce the deviation of motion delays gear and an improve the gear transmission chart.
\end{abstract}

Key words: Bevel Gears, Gleason, Kinematic Accuracy

\section{INTRODUCTION}

A proper design of each toothed gear is practically verified by its operation. In the case of bevel gears the most important quality indicators of meshing are the total contact pattern of mating and the motion graph. They are evaluated and corrected in the virtual model while determining the conditions of gear members design by making suitable modifications to the teeth flank surface of the pinion (Simon, 2008; Shih and Fong, 2008; Zhang and Wang, 2012). The selection of the geometry of the surface to the cut surface of the flank of a tooth gear can affect the shape and course of mating and the course of contact of teeth pair construction. The operational effect of the correct design and properly cut mating surfaces of teeth is the meeting of the expectations of the constructor in the capacity and nature of the work gear (De Vaujany et al., 2008). The course of the contact path and the area of the contact pattern of mating define the ability of the gear to carry loads, its low noise and sensitivity to assembly errors. A motion graph directly indicates the kinematic accuracy of the designed meshing.

\section{MODEL OF BEVEL GEAR PAIR}

The model of constructional bevel gear to mesh analysis is described in Marciniec (2003). It is a set of coordinate systems shown in Fig. 1. The system $S_{f}$ is rigidly connected to the body of the gear unit, so that its axis $Z_{f}$ coincides with the axis of rotation of the pinion $Z_{1}$. The axis $X_{f}$ should intersect the axis of rotation of the gear $Z_{2}$ at the point $O_{2}$, which - together with the point $O_{f}$ - designates a section equal to the shortest distance between the axes $(E)$, where $E$ stands for the bevel gear assembly error whose axes theoretically intersect at an angle $\Sigma$. The starting position for the systems $S_{1}$ and $S_{2}$, which are rigidly connected respectively with the pinion and the gear is a position in which the axes $X_{1}$ and $X_{2}$ have opposite directions and are aligned with the axis $X_{f}$. The system $S_{d}$ is an auxiliary system facilitates the determination of the position of the system $S_{2}$.

When meshing, the current position of the pinion and gear angles are defined by the angles of their rotations, that is $\varphi_{1}$ and $\varphi_{2}$. The values $\varphi_{1}^{(0)}$ and $\varphi_{2}^{(0)}$ of these angles designate a position which ensures contact of the tooth surfaces $\Sigma_{1}$ and $\Sigma_{2}$ at the center point $M$, in which the position $u_{12}$ reaches the nominal value calculated with the following formula:

$u_{21}=\frac{\omega_{2}}{\omega_{1}}=\frac{z_{1}}{z_{2}}$

where: $\omega_{1}, \omega_{2}$ - angular velocity of pinion and gear respectively, $z_{1}, z_{2}$ - the number of teeth of pinion and gear.

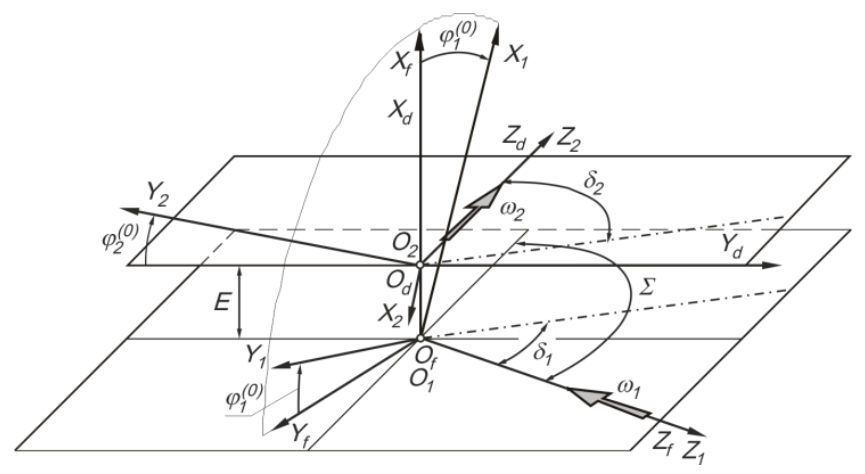

Fig. 1. Coordinate systems of bevel gear model

\section{ISSUES ON MOTION GRAPH}

The motion graph shows the relation between gear motion and the driving pinion moving at constant angular velocity (Litvin and Fuentes, 2004). The relation between the angle of gear rotation $\varphi_{2}$ and the pinion rotation angle $\varphi_{1}$ is shown in Fig. 2. In the theoretical transmission, where the surfaces of the mating teeth 
are coupled linearly and envelope each other as a result of a roll with a constant ratio, the graph will be a straight line. In addition to the theoretical case, it is necessary to assume the ideal rigidity of teeth and the right design and assembly of the gears. Such a transmission transmits the motion at a uniform rate and keeps the constant ratio (Alves et al., 2013). Therefore, the function of the motion transmission in an ideal, theoretical gear is a linear function:

$\varphi_{2}=\mathrm{u}_{21} \cdot \varphi_{1}$

Points $P_{p}$ and $P_{k}$ (Fig. 2) determine the beginning and the end of the teeth pairs contact and $\gamma_{1}$ is the angle pitch of the pinion toothing.

$\gamma_{1}=\frac{2 \pi}{\mathrm{z}_{1}}$

Point $P_{p}$ is the point of contact of the tooth root of the pinion with the tooth tip of the gear, and $P_{k}$ is the point of contact of the pinion tooth tip with the gear tooth root. Knowing the angle $\gamma_{p}$ through which the pinion will rotate during the contact tooth it is possible to determine the contact ratio which expresses the average number of teeth in contact.

$\varepsilon=\frac{\gamma_{p}}{\gamma_{1}}$

$\Delta \varphi_{2}=\varphi_{2}\left(\varphi_{1}\right)-\mathrm{u}_{21} \varphi_{1}$

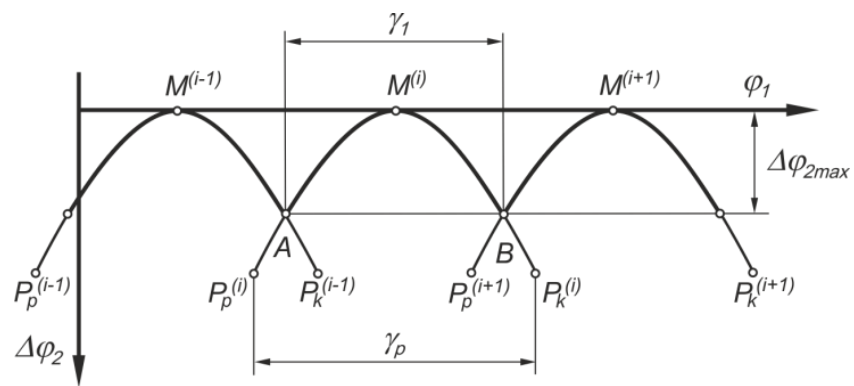

Fig. 2. Motion graph of the bevel gears pair (2)

In practice, neither gear members nor other parts of the machine unit can be made perfectly. Due to the permitted by tolerance changes of their dimensions and geometry in relation to the theoretical form, a modification of the active surface of the pinion teeth is introduced. Its aim is to reduce the sensitivity of the transmission for the errors in the position of the pinion and the gear in the pair. A negative effect of this action is that the gear motion is not uniform and it is only at the point $M$ that it reaches the assumed value $u_{21}$, while in the remaining range it is variable and dependent on the angle of rotation $\mathrm{u}_{21}\left(\varphi_{1}\right)$. The gear moves with a delay with variable speed of $\omega_{2}=f\left(\varphi_{1}\right)$ (Marciniec, 2003). Deviations of the gear angle rotation in relation to the angle resulting from the assumed constant ratio, calculated with the formula (Pisula and Płocica, 2013), are depicted by the parabola on the motion graph. This graph should have a mild course with no abrupt changes in value, and the value of the maximum deviation in the point of motion transmission should not exceed 10 seconds of arc (Litvin and Fuentes, 2004). Such a shape of the motion graph ensures a fairly uniform gear course with no sudden accelerations and decelerations.

Mating of the gear and pinion of a theoretically perfect geometry, assembled with some deviations in a construction pair, will be characterized by contact edge, and the graph becomes a so-called "sawtooth wave" (shown in Fig. 3). This situation is unacceptable because it results in a shocking character of the loading transmission and an increased toothing noisiness.

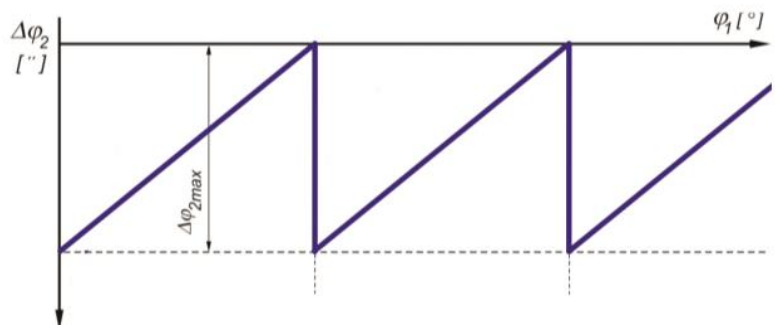

Fig. 3. "Sawtooth wave" motion graph as a result of shocking mesh

In the gear in which the motion has been modified with appropriate parameters, such phenomena do not occur even in the presence of assembly errors. The set modification of the movement of transmission is realized by providing appropriate setting values of the processing machine at the stage of the pinion processing to ensure the desired modification of the active surface of the tooth (Alves et al, 2013; Marciniec, 2003; Wang and Fong, 2005). This requires a change in the geometry of the pinion at the stage of the data preparation for the calculation process.

\section{ANALYSIS AND MODIFICATION OF MOTION GRAPH}

The issue on modeling of kinematic accuracy of the bevel gear was presented with the example of the pair 17/35 whose geometry is specified in Tab.1.

Tab. 1. Basic geometrical data of the gear $17 / 35$

\begin{tabular}{|l|c|l|l|}
\hline Quantity & $\begin{array}{l}\text { Desig- } \\
\text { nation }\end{array}$ & Pinion & Gear \\
\hline Number of teeth & $\mathrm{z}$ & 17 & 35 \\
\hline Hand of spiral & & Left & Right \\
\hline External transverse module & $m_{t}$ & $1.860 \mathrm{~mm}$ \\
\hline Pressure angle & $\alpha_{0}$ & $20^{\circ}$ & \\
\hline Shaft angle & $\Sigma$ & $90^{\circ}$ & \\
\hline Spiral angle & $\beta$ & $33^{\circ} 15^{\prime}$ \\
\hline Mean cone distance & $\mathrm{R}$ & $30.186 \mathrm{~mm}$ \\
\hline Face width & $\mathrm{b}$ & $12.00 \mathrm{~mm}$ \\
\hline External whole depth & $\mathrm{H}$ & $3.191 \mathrm{~mm}$ & $3.191 \mathrm{~mm}$ \\
\hline Clearance & $\mathrm{C}$ & $0.350 \mathrm{~mm}$ & $0.350 \mathrm{~mm}$ \\
\hline External height of tooth head & $h_{a}$ & $1.837 \mathrm{~mm}$ & $1.004 \mathrm{~mm}$ \\
\hline External height of tooth root & $h_{f}$ & $1.354 \mathrm{~mm}$ & $2.187 \mathrm{~mm}$ \\
\hline Pitch angle & $\delta$ & $25^{\circ} 54^{\prime} 23^{\prime \prime}$ & $64^{\circ} 5^{\prime} 37^{\prime \prime}$ \\
\hline Dedendum angle & $\theta_{f}$ & $0^{\circ} 30^{\prime} 58^{\prime \prime}$ & $0^{\circ} 50^{\prime} 2^{\prime \prime}$ \\
\hline Addendum angle & $\theta_{a}$ & $0^{\circ} 50^{\prime} 2^{\prime \prime}$ & $0^{\circ} 30^{\prime} 58^{\prime \prime}$ \\
\hline
\end{tabular}

The reference for making changes in the geometry of the flank surface of the pinion is the gear tooth surface, obtained by virtual cutting from the basic machine settings. The motion graph of the basic design pair is shown in Fig. 4. Further modifications to improve the kinematic accuracy are carried out in relation to the basic surface of the pinion (i.e. not to the theoretical surface). The geometry of the tooth flank surface is determined by the following 
parameters: deviation of pressure angle $\alpha$, deviation of spiral angle $\beta_{1}$, tooth flank surface deviation angle $\mathrm{T}$, profile curvature factor $\mathrm{B}_{\mathrm{w}}$ and lengthwise curvature factor $\mathrm{K}$. The changes of values of each parameter of the tooth flank surface are included in Tab. 2 - 6.

The modification of the parameters of the tooth flank surface is only possible through the modification of the parameters of its processing. Thus, once a modification of a given parameter was introduced, a program generating the technological settings for the case in question was launched. The new flank tooth surface served as the basis for the calculation of the parameters $\alpha, \beta_{1}$, T, $\mathrm{B}_{\mathrm{w}}, \mathrm{K}$.

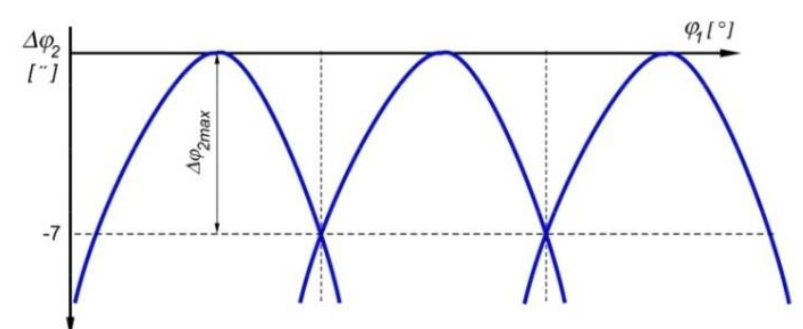

Fig. 4. Motion graph of basic construction pair

Tab. 2. Case I - change of pressure angle

\begin{tabular}{|c|c|c|}
\hline \multirow{3}{*}{ Introduced change } & Designation & Change value \\
\hline \multirow{3}{*}{ Result changes } & $\alpha$ & $7^{\prime} 4^{\prime \prime}$ \\
\cline { 2 - 3 } & $\beta_{1}$ & $-1^{\prime} 10^{\prime \prime}$ \\
\cline { 2 - 3 } & $\mathrm{K}$ & $11.5 \mu \mathrm{m}$ \\
\cline { 2 - 3 } & $B_{w}$ & $1.8 \mu \mathrm{m}$ \\
\cline { 2 - 3 } & $\mathrm{T}$ & $-1^{\prime} 28^{\prime \prime}$ \\
\hline
\end{tabular}

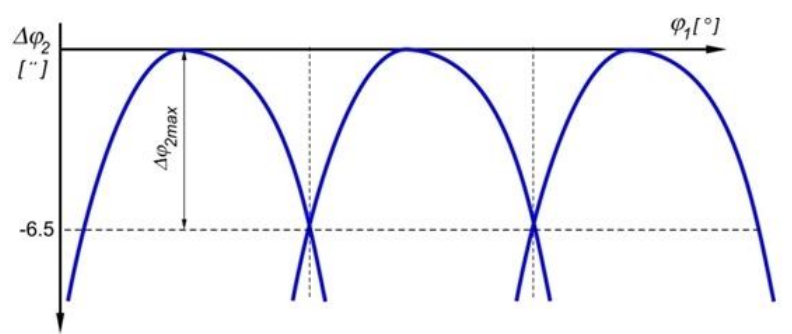

Fig. 5. Motion graph after pressure angle change

Tab. 3. Case II - change of spiral angle

\begin{tabular}{|c|c|c|}
\hline \multirow{2}{*}{ Introduced change } & Designation & Change value \\
\hline \multirow{3}{*}{ Result changes } & $\beta_{1}$ & $0^{\prime} 37^{\prime \prime}$ \\
\cline { 2 - 3 } & $\alpha$ & $3^{\prime} 42^{\prime \prime}$ \\
\cline { 2 - 3 } & $\mathrm{K}$ & $11.4 \mu \mathrm{m}$ \\
\cline { 2 - 3 } & $B_{w}$ & $1.7 \mu \mathrm{m}$ \\
\cline { 2 - 3 } & $\mathrm{T}$ & $-2^{\prime} 13^{\prime \prime}$ \\
\hline
\end{tabular}

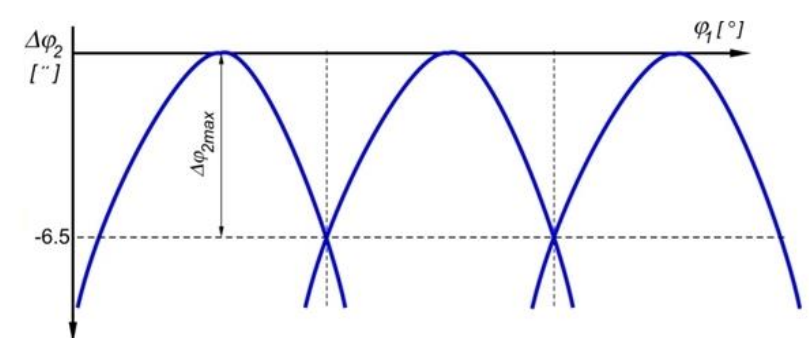

Fig. 6. Motion graph after spiral angle change acta mechanica et automatica, vol.8 no.2 (2014), DOl 10.2478/ama-2014-0017

Tab. 4. Case III - change of lengthwise curvature factor

\begin{tabular}{|c|c|c|}
\hline \multirow{3}{*}{ Introduced change } & Designation & Change value \\
\hline \multirow{4}{*}{ Result changes } & $\mathrm{K}$ & $5,4 \mu \mathrm{m}$ \\
\cline { 2 - 3 } & $\alpha$ & $4^{\prime} 21^{\prime \prime}$ \\
\cline { 2 - 3 } & $\beta_{1}$ & $-1^{\prime} 1^{\prime \prime}$ \\
\cline { 2 - 3 } & $B_{w}$ & $1.6 \mu \mathrm{m}$ \\
\hline & $\mathrm{T}$ & $-2^{\prime} 3^{\prime \prime}$ \\
\hline
\end{tabular}

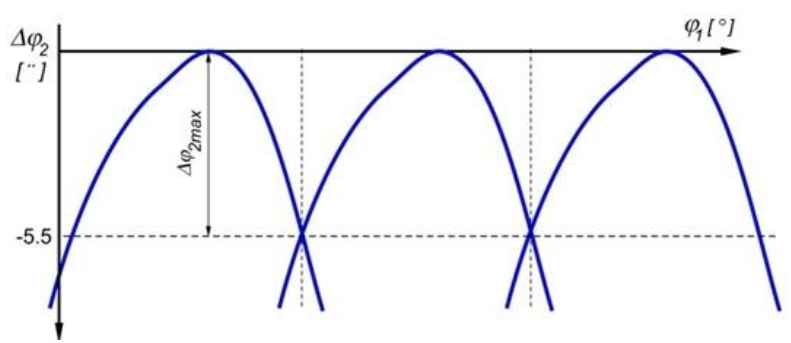

Fig. 7. Motion graph after lengthwise curvature factor change

Tab. 5. Case IV - change of profile curvature

\begin{tabular}{|c|c|c|}
\hline & Designation & Change value \\
\hline Introduced change & $B_{w}$ & $6.2 \mu \mathrm{m}$ \\
\hline \multirow{4}{*}{ Result changes } & $\alpha$ & $2^{\prime} 50^{\prime \prime}$ \\
\cline { 2 - 3 } & $\beta_{1}$ & $-1^{\prime} 9^{\prime \prime}$ \\
\cline { 2 - 3 } & $\mathrm{K}$ & $11.2 \mu \mathrm{m}$ \\
\cline { 2 - 3 } & $\mathrm{T}$ & $1^{\prime} 32^{\prime \prime}$ \\
\hline
\end{tabular}

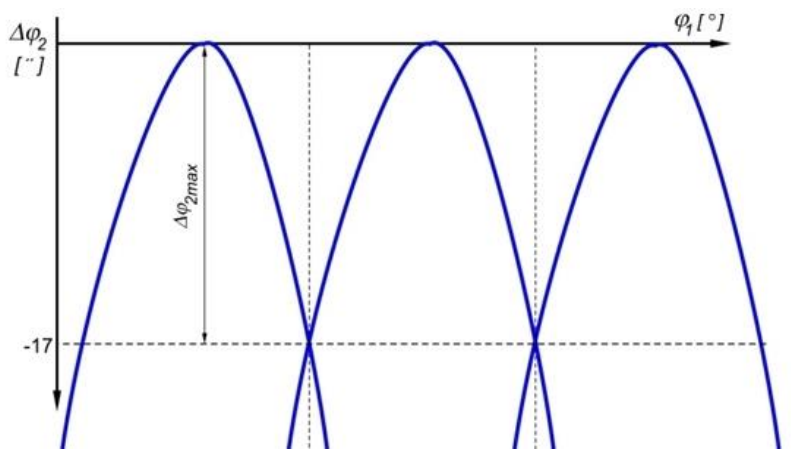

Fig. 8. Motion graph after profile factor change

Tab. 6. Case V - change of tooth flank surface deviation angle

\begin{tabular}{|c|c|c|}
\hline & Designation & Change value \\
\hline Introduced change & $\mathrm{T}$ & $2^{\prime} 40^{\prime \prime}$ \\
\hline \multirow{4}{*}{ Result changes } & $\alpha$ & $3^{\prime} 38^{\prime \prime}$ \\
\cline { 2 - 3 } & $\beta_{1}$ & $-1^{\prime} 4^{\prime \prime}$ \\
\cline { 2 - 3 } & $\mathrm{K}$ & $10.9 \mu \mathrm{m}$ \\
\cline { 2 - 3 } & $B_{w}$ & $1.3 \mu \mathrm{m}$ \\
\hline
\end{tabular}

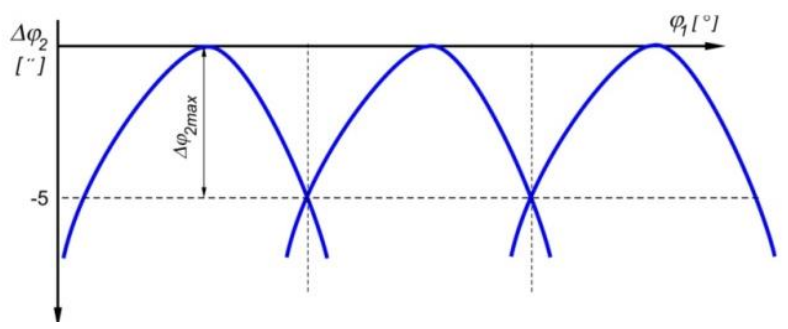

Fig. 9. Motion graph after surface deviation change 


\section{CONCLUSIONS}

The knowledge of the nature and change values in the motion graph connected with the changes of parameters in the flank tooth surface allows for a quick and conscious correction of the kinematic accuracy of the bevel gear. Regarding the analyzed gear $17 / 35$ one can draw the following conclusions:

- the increase in the deflection of the profile angle of the tooth (case I), and the change of the angle of the tooth line (case II) have little effect on motion graph. Correcting the surface in this way can slightly reduce the maximum deviation of the motion, without prejudice to its liquidity;

- lengthwise curvature change of the width of the pinion (case III) results in a significant reduction of the maximum deviation of motion, but interferes with mild motion graph, thus losing the desired uniformity of motion;

- kinematics of gear pair is very sensitive to profile factor change (case IV). Small adjustments of the profile factor cause a significant increase in motion deviations. While introducing the changes to profile factor relative to its basic value no improvement in the motion graph has been observed;

- correction of the tooth flank twist can reduce the deviation of the motion without negative changes in the shape of the graph. In comparison with the other changes that were introduced, adjusted twist has given the best kinematic accuracy of the meshing pair.

In order to reach general conclusions, further tests of the gear pairs, with different parameters of its members and different gear ratios, should be performed. Note: all changes in the geometry of the surface of the pinion cause the changes in the contact pattern (Pisula and Płocica, 2012, 2013). Therefore, the potential benefit of improving the accuracy of the kinematic should be considered in relation to the contact pattern and the transmission capacity to carry loads associated with this.

\section{REFERENCES}

1. Alves J. T., Guignand M., de Vaujany J-P. (2013), Designing and Manufacturing Spiral Bevel Gears Using 5-axis Computer Numerical Control (CNC) Milling Machines. ASME Journal of Mechanical Design, February 2013, Vol. 135, 024502.

2. De Vaujany J-P., Gugnand M., Remond D., Icard Y. (2007), Numerical and Experimental Study of the Loaded Transmission Error of a Spiral Bevel Gear, ASME Journal of Mechanical Design, Vol. 129, 195-200.

3. Litvin F., Fuentes A. (2004), Gear Geometry And Applied Theory, Cambridge University Press.

4. Marciniec A. (2003), Synthesis and analysis of meshing for Spiral Bevel Gears, Publishing House of Rzeszow University of Technology, Rzeszow (in Polish).

5. Pisula J., Płocica M. (2012), Analysis of Meshing of Bevel Gears on the Basis of a mathematical model of machining processes and Direct Simulation of Cutting in Inventor, Mechanik, 1/2012, $78-79$ (in Polish).

6. Pisula J., Płocica M. (2013), Evaluation of the Quality of Meshing for Designed Pair of Bevel Gears with Independent Design System, Mechanik, 2/2013, 138 (in Polish).

7. Shih Y. P., Fong Z. H. (2008), Flank Correction for Spiral Bevel and Hypoid Gears on a Six-Axis CNC Hypoid Generator, Journal of Mechanical Design, Transactions of the ASME, Vol. 130, 062604.

8. Simon, V.,(2008), Machine-Tool Settings to Reduce the Sensitivity of Spiral Bevel Gears to Tooth Errors and Misalignments, ASME Journal of Mechanical Design, Vol. 130, 082603.

9. Wang P. Y., Fong Z. H. (2005), Adjustability Improvement of FaceMilling Spiral Bevel Gears by Modified Radial Motion (MRM) Method, Mechanism and Machine Theory, Vol. 40, 69-89.

10. Zhang R., Wang T. (2012), The Influences of Installation Errors on Double Circular Arc Tooth Spiral Bevel Gear Using TCA Method, Journal of Convergence Information Technology (JCIT), Vol. 7, No.1, 1-10.

Research carried out in the framework of the Project "Modern material technologies applied in the aerospace industry", No. POIG.01.01.02-00015/08-00 in the Operational Programme of Innovative Economy (OPIE). Project co-financed by the European Union through the European Regional Development Fund. 